\title{
Water vapor adsorption/desorption on granulated binder-free low-module zeolites
}

\author{
T.N. Borisova, N.E. Gordina, and V.Yu. Prokof'ev, E.E. Afanas'eva, and A.V. Afineevskii \\ Ivanovo State University of Chemistry and Technology, Department of Technology of Inorganic \\ Substances, Ivanovo, Russia
}

\begin{abstract}
A characteristic of granulated LTA and SOD zeolites is given. It was determined that LTA zeolite particles have a cube shape with a size of $\sim 2 \mu \mathrm{m}$; SOD particles have an irregular shape with a size of $0.5-1 \mu \mathrm{m}$. The dimension of the coherent scattering region was calculated to be 760 $\mathrm{nm}$ for LTA and $453 \mathrm{~nm}$ for SOD. The specific surface area of LTA is 115 $\mathrm{m} 2 \cdot \mathrm{g}-1$ and SOD is $141 \mathrm{~m} 2 \cdot \mathrm{g}-1$. Static tests of granulated zeolite showed that the maximum quantity of absorbed water vapor for LTA was $\sim 30$ wt.\%, and for SOD $\sim 20 \mathrm{wt} . \%$. It was found LTA zeolite to provide adsorption of water from the gas to a dew point of $-50{ }^{\circ} \mathrm{C}$, and SOD zeolite of $-9{ }^{\circ} \mathrm{C}$. The apparent activation energies for the desorption of water on zeolites were calculated using isoconversional analysis of Friedman, Ozawa-Flynn-Wall, and Kissinger-Akahira-Sunose.
\end{abstract}

\section{Introduction}

The basic structural unit in the framework of such low-modulus zeolites as LTA and SOD is a $\beta$-cell [1]. In SOD, $\beta$-cages are linked through simple 4-membered rings. In LTA, $\beta$ cages are linked via double 4-membered rings to form simple 8 -membered rings that form an $\alpha$-cage with an input size for the $0.4 \mathrm{~nm}$ sodium form of the zeolite. $\alpha$ - and $\beta$-cages are available for water molecules; therefore, low-modulus zeolites are widely used for drying natural and other process gases [2]. Another area of application of porous adsorbents based on zeolites is the purification of rinsing wastewater and spent technological solutions from heavy metal compounds $(\mathrm{Cu}, \mathrm{Cd}, \mathrm{Ni}, \mathrm{Fe}, \mathrm{Zn}, \mathrm{Cr}, \mathrm{Co})$ and radioactive isotopes that cause irreparable damage to the environment. Practical significance consists also in the recommendations for the synthesis of granular low-modulus zeolites, which make it possible to reduce the number and duration of technological processes significantly, reduce the number of effluents generated in the synthesis process, thereby increasing the environmental issue in comparison with traditional synthesis methods.

In contrast to SOD, LTA zeolite has both $\alpha$ - and $\beta$-cages; therefore, the adsorption and desorption of water on LTA zeolite exhibits bifurcation behavior [3]. Since the sizes of these cavities differ significantly, a considerable change in the adsorption behavior in each cavity is expected. Having determined the values of enthalpy and entropy of water adsorption on LTA zeolite, B. Morris proved [4] that water adsorption occurs in zeolite cavities. The nonlinearity of water adsorption was shown in the paper [5] based on equilibrium and kinetics. 
Model water adsorption isotherms were obtained taking into account the hypothesis with two positions: one for the $\alpha$-cages and the other for the $\beta$-cages [6]. Bringing the data into Henry's law shows that in the region of the $\beta$-cage [5] they are heterogeneous, while the data [4] depose that these processes are homogeneous. The values analysis of and entropy for water adsorption in $\beta$-cages showed that this process is associated with the formation of water clusters. Water adsorption on other zeolites was studied in $[7,8]$. These papers confirmed bifurcation behavior.

In [9], a unified model of kinetic adsorption was proposed. Adsorption is described as the interaction between water and surface centers. However, the authors of [9] note deviations in the calculation of the outer water layer and equilibrium states. It has been suggested that not all elementary reactions were examined in detail, and the data are not very reliable in this area.

From the presented literature data, it can be seen that the process of adsorption of water vapor on zeolites has been studied quite well. However, these investigations were conducted on powder samples. Moreover, the process of water desorption has not been paid much attention, while this process is of great importance in the operation of zeolites. Thus, the aim of this work is to study the adsorption of water vapor kinetics in a flow-type reactor on granular low-modulus zeolites, as well as to obtain data on the desorption kinetics using isoconversion modeless analysis methods.

\section{Experimental}

Metakaolin obtained by calcining kaolin grade P-2; solid sodium hydroxide; and aluminium oxide were used for the preparation of zeolites. Zeolite granules with a diameter of $3 \mathrm{~mm}$ were prepared by using preliminary ultrasonic treatment (frequency $22 \mathrm{kHz}$ ) according to the procedures described in Ref. [10]. The main characteristics of the obtained granules of LTA and SOD zeolites are given in Table 1.

Table 1. Characteristics of the obtained granules.

\begin{tabular}{|c|c|l|l|}
\hline Parameter & & LTA & SOD \\
\hline Mechanical strength & $\mathrm{kg} /$ granule & 8,3 & 14,7 \\
\hline $\begin{array}{c}\text { Dynamic capacity by water } \\
\text { vapor }\end{array}$ & $\begin{array}{c}\mathrm{g} \mathrm{/} \mathrm{100} \mathrm{g} \\
\text { sorbent }\end{array}$ & 21,4 & 12,9 \\
\hline $\begin{array}{c}\text { Adsorption capacity for } \\
\text { nitrogen }\end{array}$ & $\mathrm{ml} / \mathrm{g}$ & 21,8 & 18,6 \\
\hline
\end{tabular}

The DRON-3M diffractometer (CuK $\alpha$-radiation) was used to carry out X-ray phase and $\mathrm{X}$-ray structural analyzes; crystalline phases were identified using the International Zeolite Association database (IZA). Scanning electron microscopy (SEM) was performed on a JSM-6460 LV device. Data from synchronous thermal analysis (STA), namely, thermogravimetry (TG), differential thermogravimetry (DTG), and differential scanning calorimetry (DSC), were obtained on STA 449 F3 Netzsch. Nitrogen adsorption/desorption isotherms at $77 \mathrm{~K}$ in the air were measured on a Micromeritics ASAP-2400.

LTA and SOD belong to cubic syngony, therefore, the unit cell parameters were calculated according to the equation:

$$
1 / d^{2}=h^{2} / a^{2}+k^{2} / a^{2}+l^{2} / a^{2}
$$

where $d$ is the interplanar distance; $h, k, l$ are Miller indices.

Integral broadening of diffraction profiles were used to determine the dimension of the coherent scattering region (CSR) and the value of the mean square microdeformations (MD), the Selyakov-Scherrer equation [11] being used:

$$
\beta_{\phi}=\lambda /\left(D_{C R S} \cos \Theta\right)+4 \varepsilon \operatorname{tg} \Theta,
$$


where DCRS is the size of the CSR; $\varepsilon$ is the value of MD; $\Theta$ is the position of the center of gravity of the sample profile. This equation is transformed to a linear form:

$$
\beta_{\phi} \cos \Theta=\lambda / D_{S R S}+4 \varepsilon \sin \Theta .
$$

To use this equation, you must have 2 or more profiles.

The specific surface area and pore volume were determined using data on nitrogen adsorption and desorption at $77 \mathrm{~K}$ [12].

The kinetics of water vapor adsorption on granulated zeolite was studied in a flow-type setup at three temperatures and a space velocity of 20,000 s-1. Air was used as a model gas. The contact time of the gas phase with the zeolite layer was varied, changing the number of granules loaded into the column. To describe the kinetics of drying, the following equation was chosen:

$$
\mathrm{d} C / \mathrm{d} \tau=k \cdot C^{n},
$$

where $C$ is the concentration of water vapor in the $\operatorname{air}\left(\mathrm{mg} \cdot \mathrm{m}^{3}\right) ; k$ is the rate constant; $n$ is the reaction order.

To study heterogeneous processes (including desorption), non-isothermal modeless methods have been widely used [13]. Under the condition of a linear increase in temperature over time, the reaction rate in the solid is described by the well-known general equation [14]:

$$
\mathrm{d} x / \mathrm{d} \tau=\beta \mathrm{d} x / \mathrm{d} \tau=\mathrm{A}_{0} f(x) \exp (-E / R T),
$$

where $x$ is the conversion extent; $\beta$ is the heating rate; $f(x)$ is the differential conversion function; $A_{0}$ is the pre-exponential factor in the Arrhenius equation; $E$ is the activation energy; $R$ is the gas constant.

The conversion extent according to thermogravimetric measurements can be calculated by the equation:

$$
x_{j}=\left[m\left(\tau_{s}\right)-m\left(\tau_{j}\right)\right] /\left[m\left(\tau_{s}\right)-m\left(\tau_{f}\right)\right],
$$

where $m\left(\tau_{s}\right)$ is the signal at the initial time moment $\tau_{s} ; m\left(\tau_{j}\right)$ is the signal at an intermediate point in time $\tau_{j} ; m\left(\tau_{f}\right)$ is the signal at a finite time instant $\tau_{f}$.

For non-isothermal conditions, Friedman proposed [13] to use the logarithm of the conversion rate $\mathrm{d} x / \mathrm{d} \tau$ as a function of the corresponding temperature:

$$
\left.\ln (\mathrm{d} x / \mathrm{d} \tau)\right|_{x=x j}=\ln A_{0}-E / R T_{k j}+\left.\ln f\left(\mathrm{x}_{j}\right)\right|_{x=x j}
$$

As the function $\mathrm{f}(\mathrm{x})$ is constant in the last term for the given $\mathrm{xj}$, then the graph of equation (7) from $1 / \mathrm{T}$ results in a straight line with a slope of $B=-E / R$. Since the reaction rate is used directly in this analysis, it refers to differential methods. (5):

Integral isoconversion analyses of non-isothermal data are based on equation integration

$$
G(x)=A_{0} E / \beta R \times p(z),
$$

where $z=E / R T ; p(z)$ is the so-called temperature integral. The methods used differ depending on the approximation of this integral.

One of these methods is the Ozawa - Flynn - Wall (OFW) analysis [15, 16], which is based on the Doyle approximation [17]:

$$
\ln \beta_{j}=\ln \left(A_{0} E / \mathrm{R}\right)-\ln G\left(x_{j}\right)-5.3305+1.052 E / R T_{k j} .
$$

Another integral method is the Kissinger - Akahira - Sunose (KAS) analysis [18, 19], where the integral $p(z)$ is expressed using the Coats - Redfern approximation [20]:

$$
\ln \left(\beta_{j} / T_{k j}^{2}\right)=\ln \left(A_{0} R / E\right)-\ln \left(x_{j}\right)-5.3305-E / R T_{k j} \text {. }
$$

From equations (9) and (10) it can be seen that for a number of measurements at heating rates $\beta_{1} \ldots \beta_{j}$ for fixed values of the conversion extent of $x=x_{k}$, the graphs of the functions $\ln \beta_{j}=f\left(1 / T_{k j}\right)$ and $\ln \left(\beta_{j} / T_{k j}{ }^{2}\right)=f\left(1 / T_{k j}\right)$ result in a straight line. $T_{j k}$ represents the temperatures at which the conversion $x_{k}$ is reached at the heating rate $\beta_{j}$. The slope of the lines is directly proportional to the activation energy. The calculation of the mean value over all heating rates $\beta_{j}$ gives values for $\ln A_{0}$. 


\section{Results and discussion}

X-ray powder diffraction data show that the samples are LTA and SOD zeolites (Figure 1), and the unit cell parameters correspond to the data given in the IZA database for LTA and SOD zeolites (Table 2). SEM images of zeolites show that LTA zeolite particles have a shape close to a cube and a size of about $2 \mu \mathrm{m}$ (Figure 1, a). SOD is an irregularly shaped particle with a size of $0.5-1 \mu \mathrm{m}$ (Figure 1,b). Calculation of CSR dimensions and comparison with SEM data show that LTA zeolite particles are agglomerates of four or more crystallites, and SOD zeolite particles consist of one or 2-4 crystallites (Table 2). Note that the defectiveness of the LTA zeolite is 3 times less than the defectiveness of the SOD zeolite (Table 2). The specific surface area, as well as the total pore volume of the LTA zeolite, is approximately $20 \%$ larger than that of SOD; moreover, SOD zeolite has practically no micropores (Table 2 ).

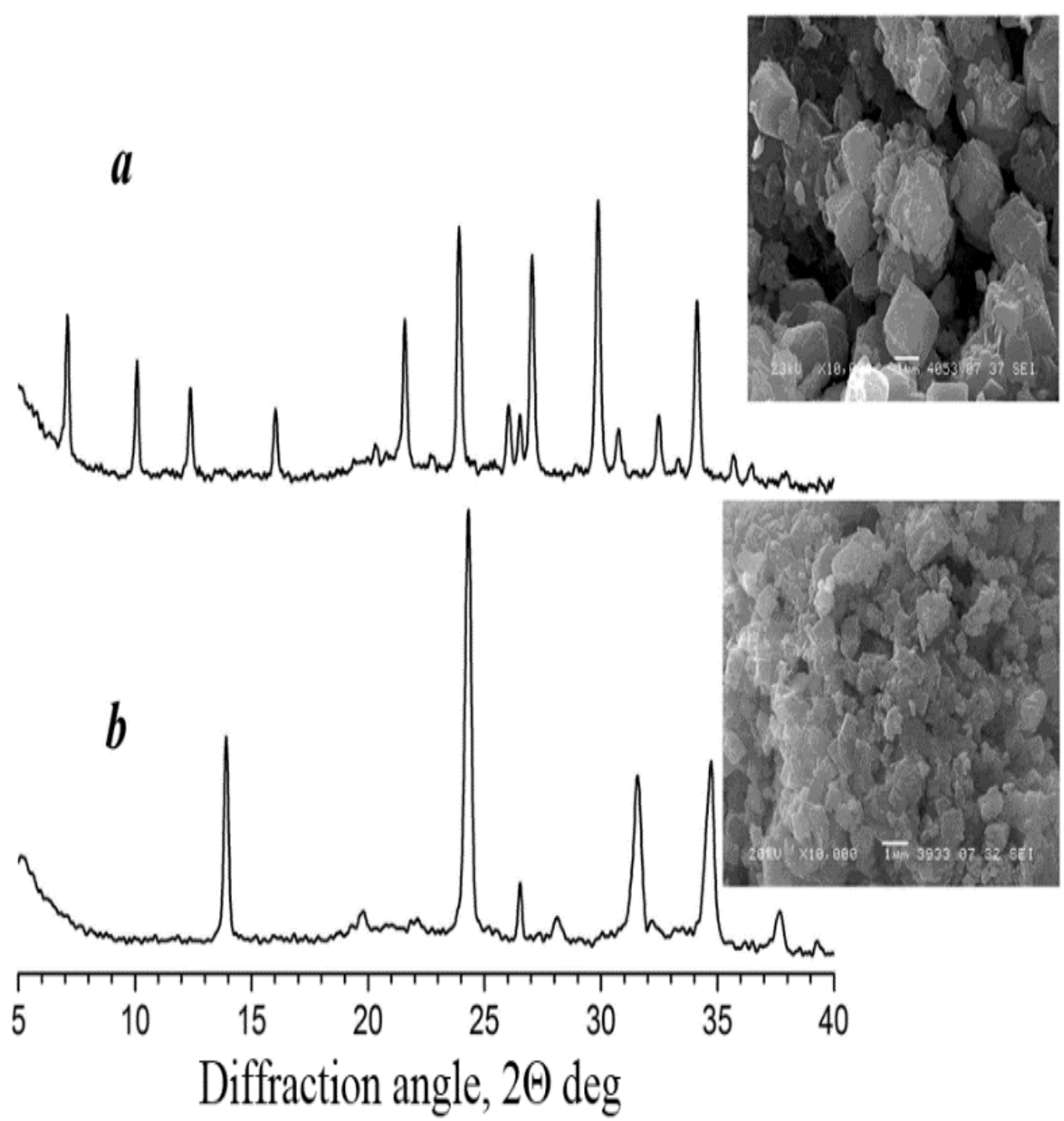

Fig. 1. X-ray diffraction patterns (CuK $\alpha$ radiation) and SEM images (1 $\mu \mathrm{m}$ scale) (a) LTA and (b) SOD zeolites. 
Table 2. Characterization of the crystalline and porous structure (by BET) of granulated zeolites.

\begin{tabular}{|c|c|c|c|c|}
\hline Parameters & & & LTA & SOD \\
\hline Crystal lattice parameter & $a$ & $(\AA)$ & 24.76 & 8.88 \\
\hline Dimension of the coherent scattering region & $D_{C S R}$ & $(\mathrm{~nm})$ & 780 & 462 \\
\hline Values of microdeformations & $\varepsilon$ & $(\%)$ & 0.05 & 0.15 \\
\hline Specific surface area & $S$ & $\left(\mathrm{~m}^{2} \cdot \mathrm{g}^{-1}\right)$ & 148.8 & 115.6 \\
\hline Total pore volume & $V_{\text {tot }}$ & $\left(\mathrm{cm}^{3} \cdot \mathrm{g}^{-1}\right)$ & 0.041 & 0.033 \\
\hline Micropore volume & $V_{m p}$ & $\left(\mathrm{~cm}^{3} \cdot \mathrm{g}^{-1}\right)$ & 0.007 & 0.001 \\
\hline
\end{tabular}

Isotherms of adsorption and desorption of water vapor on zeolite granules have hysteresis and are of type IV, which indicates the presence of capillary condensation in zeolite granules (Figure 2). The maximum moisture capacity of the LTA zeolite is about 30 wt.\%, which is 1.5 times more than that of SOD. These results correlate well with the data obtained on the flow-type setup. So, for LTA zeolite granules at air temperature, the dew point reaches $-50^{\circ} \mathrm{C}$, and for SOD only $-9^{\circ} \mathrm{C}$ (Table 3). These facts are explained by the presence of SOD in the zeolite only $\beta$-cavities, while LTA zeolite also has $\alpha$-cavities with a higher adsorption capacity. Therefore, it's not the developed surface of the sorbent that is critical for the adsorption process, but the presence of regular cavities in the zeolite framework.

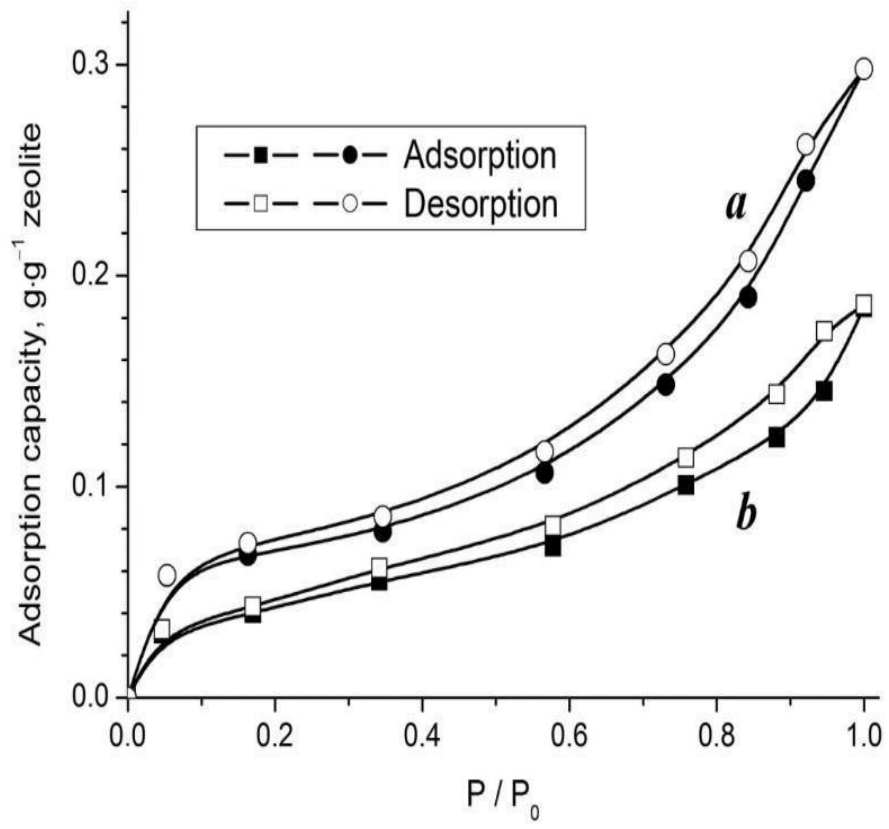

Fig. 2. The curves of adsorption and desorption of water vapor on (a) LTA and (b) SOD zeolites.

Table 3. Kinetic parameters of water vapor adsorption on granulated zeolites (volume rate $20000 \mathrm{~s}^{-1}$ ). 


\begin{tabular}{|c|l|l|l|l|l|}
\hline Zeolite type & $\begin{array}{l}\text { Drying } \\
\text { process } \\
\text { temperature, } \\
{ }^{\circ} \mathrm{C}\end{array}$ & $\begin{array}{l}\text { Reached dew } \\
\text { point, }{ }^{\circ} \mathrm{C}\end{array}$ & $\begin{array}{l}\text { Apparent } \\
\text { activation } \\
\text { energy, } \\
\mathrm{kJ} \cdot \mathrm{mol}^{-1}\end{array}$ \\
\hline $\mathrm{NaA}$ & 20 & -50.0 & 44.4 & $\begin{array}{l}\text { Preexponential } \\
\text { factor }\end{array}$ & $\begin{array}{l}\text { Reaction } \\
\text { order, } n\end{array}$ \\
\hline & 25 & -47.0 & & & $2.74 \cdot 10^{7}$ \\
\hline & 30 & -36.5 & & & 0.9 \\
\hline SOD & 20 & -9.2 & 48.0 & $5.51 \cdot 10^{7}$ & 0.2 \\
\hline & 25 & -4.2 & & & \\
\hline & 30 & 0.7 & & & \\
\hline
\end{tabular}

Processing of kinetic studies data using equation (4) shows that for both types of zeolites, the reaction order is of fractional importance (Table 3). This indicates a multistage process of water vapor adsorption on zeolite granules. The values of the apparent activation energy calculated using the Arrhenius equation amounted to about $50 \mathrm{~kJ} \cdot \mathrm{mol}-1$. This indicates that the limiting stage of the drying process on zeolite granules is the diffusion of water vapor [21].

The desorption process was investigated by isoconversion analyses using STA data on zeolites previously saturated by water vapor. For LTA zeolite, water desorption is observed to a temperature of $275.5^{\circ} \mathrm{C}$ and proceeds in two stages (Fig. 3,a). The first stage has an extremum on the DTG curve at a temperature of about $50^{\circ} \mathrm{C}$, and the second extremum is at a temperature of about $150^{\circ} \mathrm{C}$. For SOD zeolite, the removal of adsorbed water also occurs in two stages up to a temperature of $304^{\circ} \mathrm{C}$ (Fig. 3,b). The first stage corresponds to an extremum on the DTG curve at a temperature of about $95^{\circ} \mathrm{C}$; the second stage corresponds to a peak at a temperature of about $190^{\circ} \mathrm{C}$. In both zeolites in the first stage, water is removed from the pores and physically adsorbed on the surface of the particles. With a further increase in temperature, water occluded in the $\alpha$ - and $\beta$-cages of zeolites is desorbed in the second stage. At higher temperatures, chemically bound water is dehydrated in zeolite frameworks. 


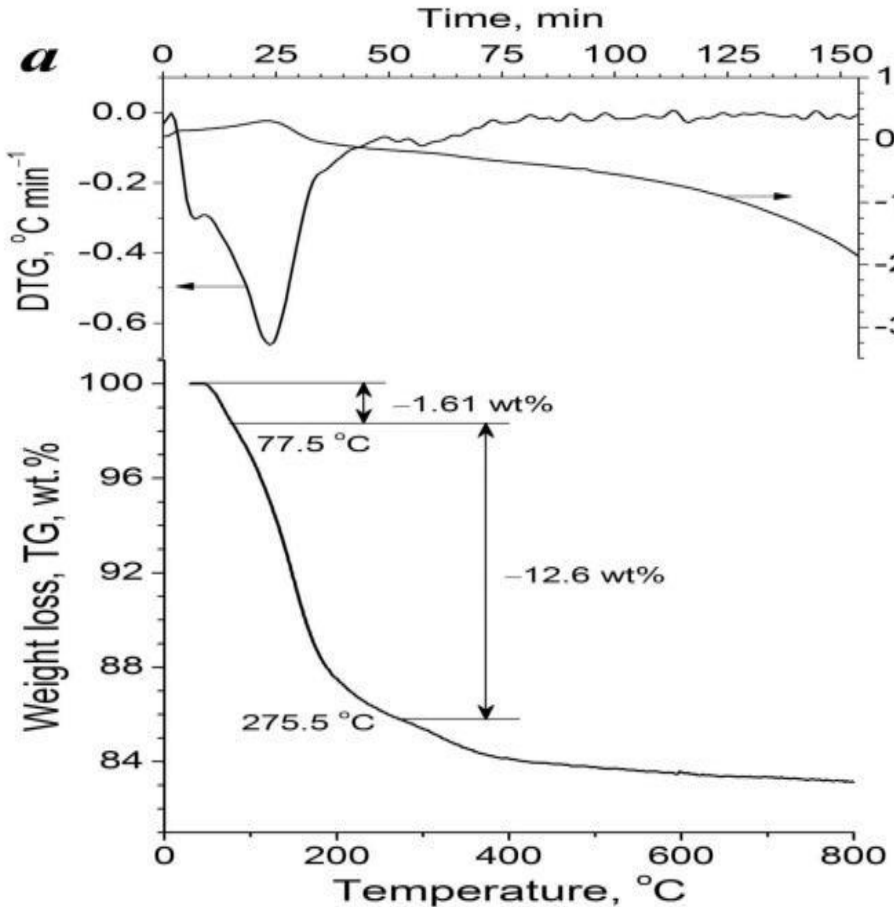

Time, $\min$

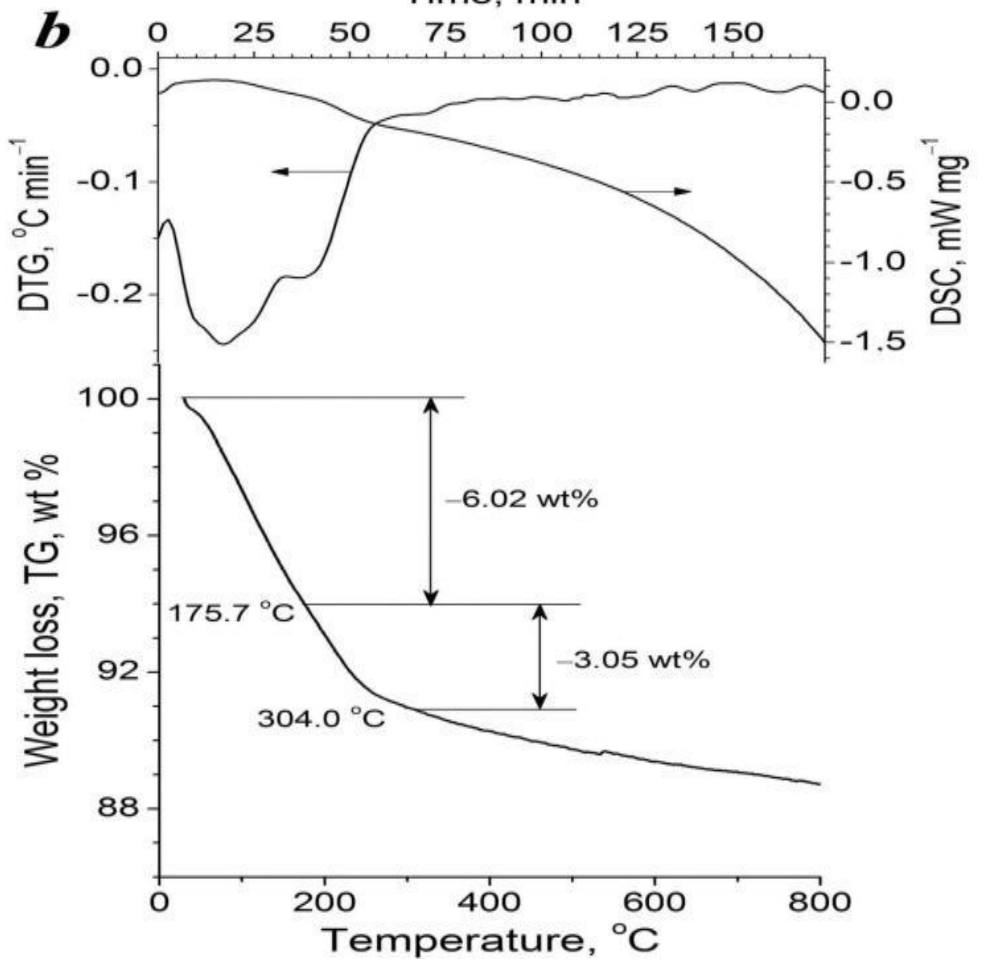

Fig. 3. Data from synchronous thermal analysis of (a) LTA and (b) SOD zeolites. 
Figure 4 shows the dependences of the conversion extent (desorption) on the temperature of the non-isothermal process. Attempts to describe these dependencies by formal kinetic equations have been unsuccessful. This is explained by the multistage mechanism of water desorption on zeolite granules. Part of the water is bonded due to weak interactions of physical adsorption, another part of the water remains in the cavities of the zeolite, which has a localized solid state in the cavities [22].
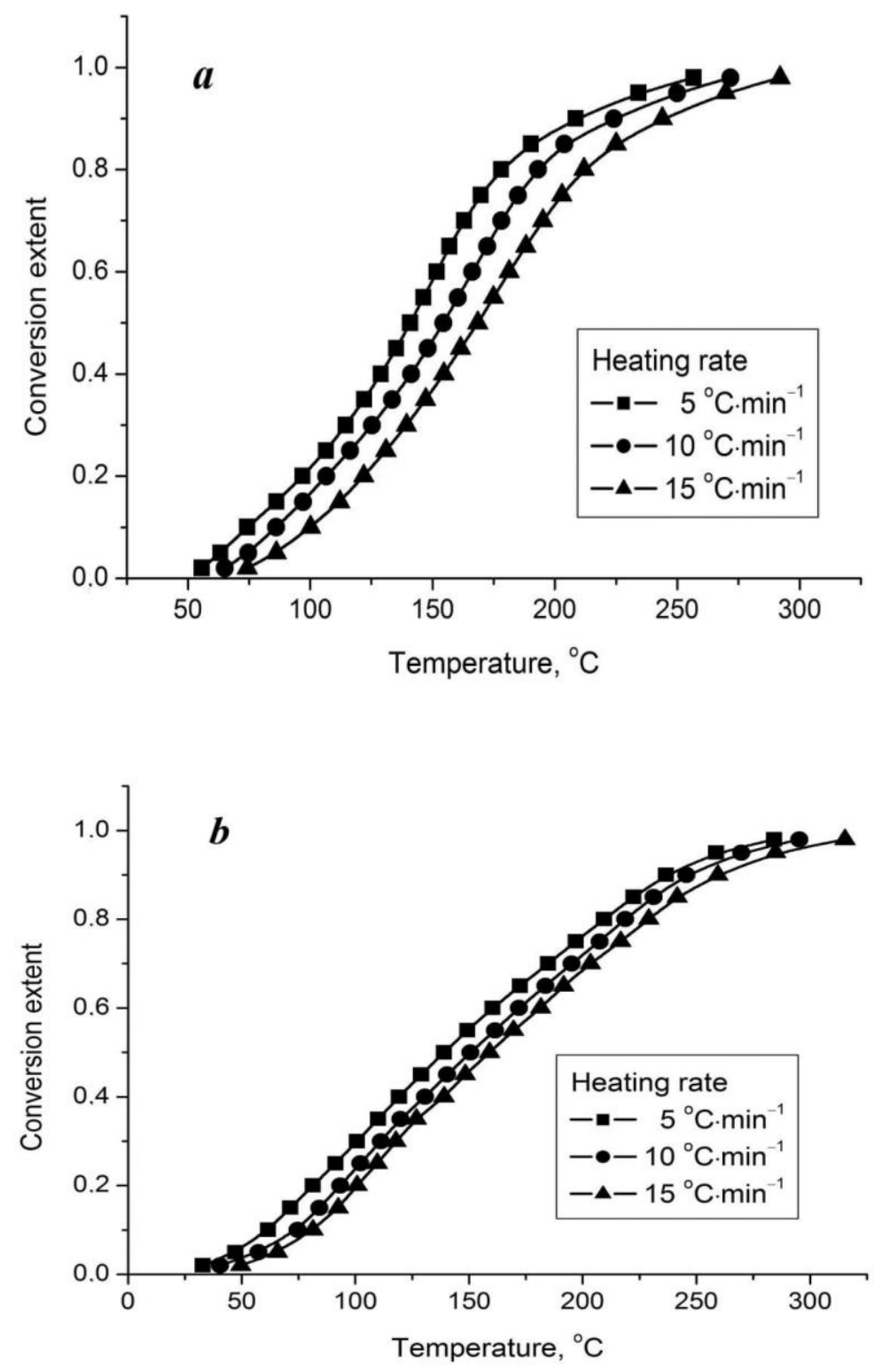

Fig. 4. Dependence of conversion extent (desorption) on temperature according to CTA for (a) LTA and (b) SOD zeolites. 
Figure 5 presents the results of calculations of the apparent activation energy of the process of water desorption on LTA and SOD zeolites using the Friedman (equation 7), OFW (equation 9) and KAS (equation 10) analyzes. You can see that the values of the apparent activation energy obtained by various analyzes are quite close.

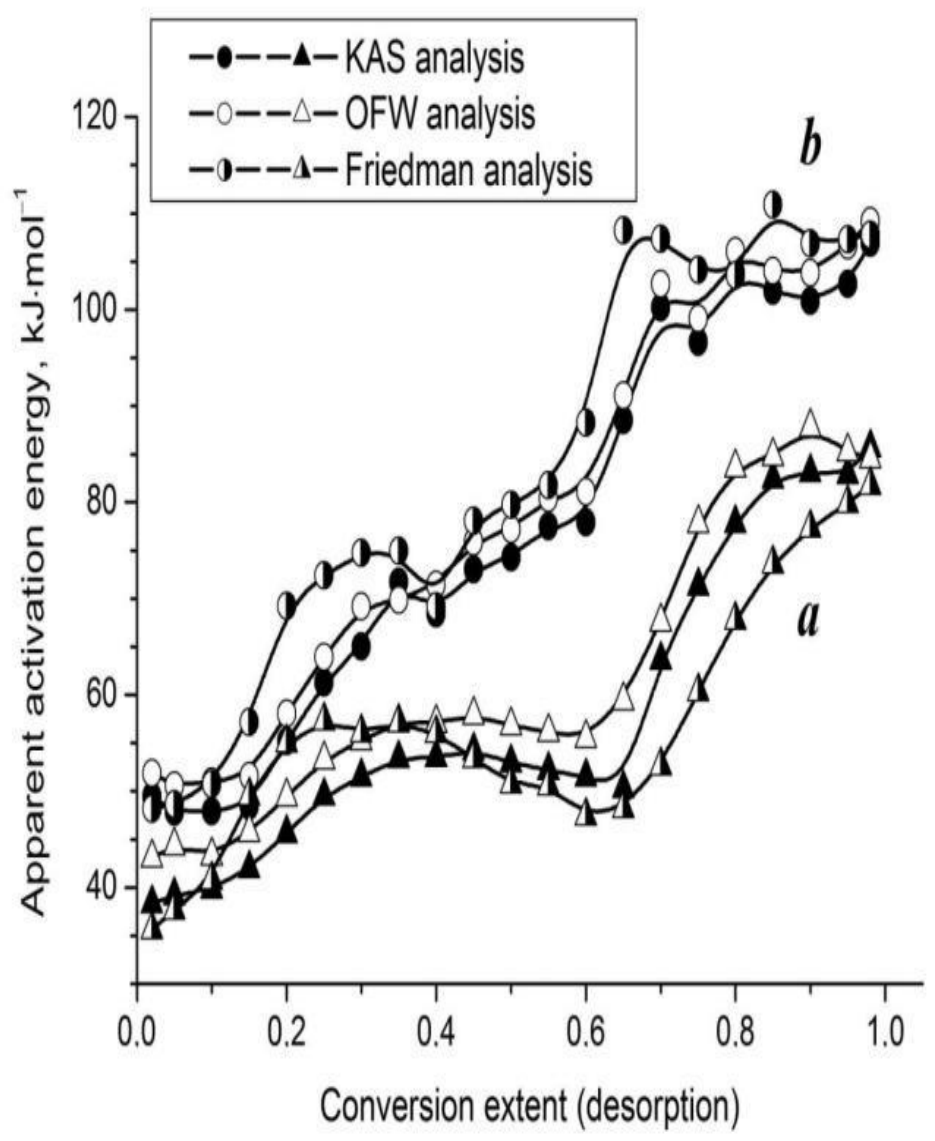

Fig. 5. The dependences of the apparent activation energy on the extent conversion (desorption), calculated according to CTA data by KAS, OFW, and Friedman analyzes for zeolites (a) LTA and (b) SOD.

For LTA and SOD zeolites, the activation energies at low conversion extent (LTA $\sim 0.2$; SOD $~ 0.3$ ) have small values that correspond to desorption of physically bound water (Figure 5). A further increase in the activation energy can be explained by desorption of water from zeolite cavities. For LTA zeolite in the range of conversion extent $0.2-0.85$, the activation energies are 50-60 $\mathrm{kJ} \cdot \mathrm{mol}^{-1}$ (Figure 5,a). This corresponds to the desorption of water molecules from $\alpha$-cages. A further increase in the activation energy of water desorption to $80 \mathrm{~kJ} \cdot \mathrm{mol}^{-1}$ is associated with the removal of occluded water from $\beta$-cages of LTA zeolite. For the SOD zeolite in the range of conversion extent of $0.3-0.7$, the values of the activation energy of water adsorption are $70-80 \mathrm{~kJ} \cdot \mathrm{mol}^{-1}$ (Figure $5, b$ ). These values can be attributed to the removal of water molecules from the intercagelar space of SOD zeolite. At conversion extent greater than 0.7 for SOD zeolite, the activation energy values increase 
to $100-110 \mathrm{~kJ} \cdot \mathrm{mol}^{-1}$ (Figure $5, b$ ). Here, the water occluded in the $\beta$-cages of SOD zeolite is removed.

\section{Conclusions}

Thus, it has been shown that the particles of LTA zeolite have a shape close to the cube and a size of about $2 \mu \mathrm{m}$, and the CSR dimension is $760 \mathrm{~nm}$; SOD zeolite particles have an irregular shape with a size of $0.5-1 \mu \mathrm{m}$ and a CSR dimension of $453 \mathrm{~nm}$. The specific surface area of LTA $(115 \mathrm{~m} 2 \cdot \mathrm{g}-1)$ and SOD $(141 \mathrm{~m} 2 \cdot \mathrm{g}-1)$ zeolites have been also determined. The adsorption and desorption isotherms of water vapor on zeolites have been obtained and it has been found that the curves are of type IV, and the maximum amount of absorbed water vapor for LTA was $\sim 30 \mathrm{wt} . \%$ and for SOD it was $\sim 20 \mathrm{wt} . \%$.

Tests of zeolites in a flow-through setup have shown that LTA zeolite provides adsorption of water from the gas phase to a dew point of $-50^{\circ} \mathrm{C}$, and SOD zeolite only up to $-9^{\circ} \mathrm{C}$. The values of the apparent activation energy of the adsorption process were calculated for both zeolites; they amounted to up to $50 \mathrm{~kJ} \cdot \mathrm{mol}-1$.

By using synchronous thermal analysis, it has been shown that for LTA zeolite, water desorption occurs up to $275.5^{\circ} \mathrm{C}$, and for SOD zeolite, adsorbed water is being removed up to $304^{\circ} \mathrm{C}$. It has been found that these processes proceed in two stages.

The apparent activation energy for water desorption on zeolites has been calculated by Friedman, OFW, and KAS analyzes. It has been shown that all three analyzes give similar results. It has been found that with conversion extent the activation energy values do not exceed $60 \mathrm{~kJ} \cdot \mathrm{mol}-1$, which corresponds to the desorption of physically bound water. An increase in activation values up to $110 \mathrm{~kJ} \cdot \mathrm{mol}-1$ (for SOD) and to $80 \mathrm{~kJ} \cdot \mathrm{mol}-1$ (for LTA) is associated with the removal of water from the $\alpha$ - and $\beta$-cages of zeolites.

This work was supported by the Ministry of Science and Higher Education of the Russian Federation (Project № FZZW-2020-0010). The reported study was funded by RFBR according to the research project № 20-33-90075.

\section{References}

1. D.W. Breck, Zeolite molecular sieves: structure, chemistry and uses. (New York: John Wiley, 1974).

2. A. Pfenninger, Manufacture and use of zeolites for adsorption processes. Karge H.G., Weitkamp J. (eds.). Molecular Sieves - Science and Technology, Structures and Structure Determination, 2, 163-198 (1999).

3. J.A. Rabo, Zeolite chemistry and catalysis. (Washington: American Chemical Society, 1976).

4. B.J. Morris, Heats of sorption in the crystalline linde-A zeolite-water vapor system. Colloid Interface Sci. 28(1): 149-155 (1968).

5. A. Gorbach, M. Stegmair, G. Eigenberger, Measurement and modeling of water vapor adsorption on zeolite 4A-equilibria and kinetics. Adsorption, 10: 29-49 (2004).

6. K.F. Loughlin, Water isotherm models for 4A (NaA) zeolite. Adsorption. 15: 337-353 (2009).

7. Y.K. Ryu, S.J. Lee, J.W. Kim, Ch.-H. Lee, Adsorption equilibrium and kinetics of $\mathrm{H}_{2} \mathrm{O}$ on zeolite 13X. Korean J. Chem. Eng. 18(4): 525-530 (2001).

8. M. Tatlier, G. Munz, S.K. Henninger, Relation of water adsorption capacities of zeolites with their structural properties. Micropor. Mesopor. Mater. 264: 70-75 (2018). 
9. M. Gaulke, V. Guschin, S. Knapp, S. Pappert, W. Eckl, A unified kinetic model for adsorption and desorption applied to water on zeolite. Micropor. Mesopor. Mater. 233: 39-43 (2016).

10. Gordina, N.E. \& Prokof'ev, V.Yu. \& Kul'pina, Yu.N. \& Petuhova, N.V. \& Gazahova, S.I. \& Hmylova, O.E. 2016. Effect of ultrasound on the synthesis of low-modulus zeolites from a metakaolin. Ultrason. Sonochem. 33: 210-219.

11. T. Ekström, C. Chatfield, W. Wruss, M. Maly-Schreiber, The use of X-ray diffraction peak-broadening analysis to characterize ground $\mathrm{Al}_{2} \mathrm{O}_{3}$ powders. J. Mater. Sci. 20(4): 1266-1274 (1985).

12. J.U. Keller, R. Staudt, Boston gas adsorption equilibria. Experimental methods and adsorptive isotherms. (Springer-Verlag US, 2005).

13. T. Ozawa, Thermal analysis - review and prospect. Thermochim. Acta. 355(1-2): 3542 (2000).

14. F. Baitalow, H.-G. Schmidt, G. Wolf, Formal kinetic analysis of processes in the solid state. Thermochim. Acta. 337(1-2): 111-120 (1999).

15. T. Ozawa, A new method of analyzing thermogravimetric data. Bull. Chem. Soc. Jpn. 38: 1881-1886 (1965).

16. J.H. Flynn, L.A. Wall, A Quick, Direct method for the determination of activation energy from thermogravimetric data. J. Polymer Sci. B: Polymer Lett. 4: 323-328 (1966).

17. C.D. Doyle, Kinetic analysis of thermogravimetric data. J. Appl. Polymer Sci. 5: 285298 (1961).

18. H.E. Kissinger, Variation of peak temperature with heating rate in differential thermal analysis. J. Res. Natl. Bur. Stand. 57(4): 217-224 (1956).

19. T. Akahira, T. Sunose, Method of determining activation deterioration constant of electrical insulating materials. Res. Report Chiba Inst. Technol. 16: 22-31 (1971).

20. A.W. Coats, J.P. Redfern, Kinetic parameters from thermogravimetric data. Nature. 201: 68-69 (1964).

21. S.R. Morrison, Adsorption. (In Morrison S.R. (ed.). The Chemical Physics of Surfaces. Boston: Springer, 223-262, 1977).

22. M.M. Dubinin, E.G. Zhukovskaya, K.O. Murdma, Investigation of the adsorption properties and secondary porous structure of adsorbents exhibiting molecular sieve action. Communication 12. Specific peculiarities of microporous adsorbents in the adsorption of vapors of various substances. Bul. Acad. Sci. USSR, Div. chem. sci. 15(4): 590-596. (1966). 